\title{
Influence of fermentative modification of rice flour starch on bread quality for patients with celiac disease
}

\section{Iryna Medvid, Olena Shydlovska, Viktor Dotsenko}

\author{
National University of food Technologies, Kyiv, Ukraine
}

Keywords:

Celiac disease

Bread

Hydrolysis

Starch

$\alpha$-amylase

Glucoamylase

\section{Article history:}

Received 20.09.2017

Received in revised

form 30.11.2017

Accepted 29.12.2017

\section{Corresponding \\ author:}

Iryna Medvid

E-mail:

Irenamedvid@

bigmir.net

DOI: $10.24263 / 2304-$

974X-2017-6-4-5

\section{Abstract}

Introduction. The expedient use of ferments with amylolytic activity for carbohydrate composition modification of rice flour aiming to improve the quality of gluten-free bread is scientifically based.

Materials and methods. Rice flour starch has been hydrolyzed with the help of mushroom $\alpha$-amylase and glucoamylase. General amount of saccharides has been determined by iodometric method. Dextrin contents - by their ability to be precipitated in conditions of different concentrations of ethanol in the solution. The course of microbiological processes in the dough has been examined by its gasification ability using volumetric method and general acidity using titration method.

Results and discussion. The use of $\alpha$-amylase in amount of $0,005 \%$ and glucoamulase in amount of $0,03 \%$ to mass of rice flour causes sugar accumulation in amount of 5,5-6\%, which is necessary for the intensification of course of microbiological processes in the dough. To hydrolyze the starch more fully, it is expedient to prepare a semi-finished product hydrolysate with $50 \%$ of rice flour from its recipe humidity of $65 \%$ with further kneading the dough on its basis. To accumulate monosaccharides and disaccharides to the amount, which is optimal for active yeast functionality and for improvement of gasification in the dough, duration of rice flour starch hydrolysis while preparing the semi-finished product, hydrolysate is 2 hours.

The products of rice flour starch hydrolysis, which were created as a result of fermentative modification by $\alpha$-amylase and glucoamylase, particularly monosaccharides and disaccharides, intensify the process of dough fermentation, which is affirmed by increase of $\mathrm{CO}_{2}$ for $57,8 \%$ and increase of acidity for 0,6 degr. in comparison to control example, consequently to this the ready-made products are characterized by structurally mechanical quality scores. Increase of dextrin amount in the dough influences deceleration of starch retrogradation while keeping ready-made products.

Conclusions. Hydrolyzation of rice flour starch with the help of amylolytic ferments in preparation of a bread for patients suffering from celiac disease helps to intensify microbiological processes in the dough, to improve quality scores of ready-made products and prolonging of their expiration date. 


\section{Introduction}

Changes in the nature of nutrition, caused by peculiarities of modern way of life and work are becoming the reason of more intensive spreading of chronical noninfectious disturbance of an organism's normal vital activity. The use of special products for nutrition, among of which a special role is played by the products for the category of people with diseases of intolerance to some food components (diabetes, celiac disease, phenylketonuria etc.) is one of effective and efficient ways of correction and prophylaxis of different diseases.

Celiac disease is a progressive autoimmune ailment, which is spread on $0,9-1,2 \%$ of population in European regions, Northern and Southern America, Northern Africa and Indian subcontinent $[1,2]$, caused as a result of gluten introduction to people's genetically inclined organisms. The group of toxic grain proteins for people suffering from celiac disease is denoted by the term of "gluten", which includes wheat prolamins (gliadin), rye (secalin), and barley (hordein) [3], as they are characterized by high content of proline and glutamine in the structure of protein molecule. Wheat glutenin, which consists of gliadinlike subunits conjugated by disulfide bond, is toxic as well. Gluten consumption by patients with celiac disease leads to villi atrophy and damage to the mucus membrane of small intestine, which is accompanied by malabsorption of many important nutrients $[4,5]$. It may lead to diseases related to digestive disorders, such as osteoporosis, type I diabetes, skin maladies $[3,6]$. Despite considerable scientific progress in prevention of celiac disease symptoms displays, strict adherence to the gluten-free diet during the whole patient's life is the only treatment method of this disease, that leads to the clinical recovery and reduction of mucus membrane $[7,8]$.

Besides, in Ukraine the production of dietary foods for patients with celiac disease is not set up. The most burning problem is to provide them with gluten-free baked goods, which have wheat flour in their contents as a main component, that is forbidden to consume. Gliadin and glutenin swell while the dough from wheat flour is being kneaded, making gluten, which joins dampish starch grains with each other, creating a frame with spatial structure, that provides with developed porosity of crumb and uniformity of ready product $[6,9]$. However, taking into the consideration the toxicity of these goods for the patients with celiac disease, there's a need of full exchange of the flour by raw stuff with gluten-free cereals.

Rice flour is an alternative for gluten raw stuff (wheat, rye and barley) in the production of gluten-free bread. Rice product of processing do not contain prolamin fraction of "gluten", that can be allergic, with digestive disorders (celiac disease), and that's why they're used in dietary foods for people of all ages. Rice flour has soft taste, white color, high digestibility and hypoallergic properties and is the source of plant proteins, full in amino acid composition, contains natrium, potassium, magnesium, vitamins $\mathrm{B}_{1}, \mathrm{~B}_{2}$ and PP $[6,10]$. Nevertheless, its use in bakery is limited by impossibility to form the flour with structural mechanical properties and to provide with high quality of the goods [23]. It means, that the problem of searching for new ways of improving the quality of bread from rice flour for the patients with celiac disease is rather burning and actual.

\section{Analysis of literary data and problem statement}

Analysis of scientific research conducted with the aim of improving the quality of bread from rice flour shows the possibility to use it in the technology of different nutritional supplements: hydrocolloids (hydroxymethyl propyl cellulose, xanthan and guar gum, 
modified starches) and emulsifier (glycerin ester, diacetyl and fatty acids (DATEM), sodium stearoyl actinate, distilled monoglycerides, lecithin), and some of the ferments (transglutaminase, papain, bacillolysin, subtilisin) [6, 9, 11-13]. The use of methods, which allow to modify the properties of the main chemical components of gluten-free flour with the help of ferments is an actual field in production technology of bakery for patients with celiac disease [9]. The use of the methods in production of gluten-free bread has been limited for a long time, as wheat flour and starch were the carriers of these supplements. However, appearance of ferments, which even do not contain microquantity of gluten, has opened new perspectives for improving quality of bakery with the help of these preparations. Scientists offered to use a ferment transglutaminase as a former of the structure to prepare rice rough for bread. It is able to bond proteins of different origin: casein and milk albumins, animal protein of eggs and milk, soy and wheat protein. Adding transglutaminase leads to crosslinking of proteins, which allows to create gluten-like chain, by reaction catalysis of forming of specific isopeptide bond between carboxyamide group of glutamine and amino group of lysine [12].

Nowadays research in the field of improving bread quality with the help of ferments of amylolytic action, that hydrolyze flour starch and as a result the content of fermented sugars in dough gets higher, is actively developing [14]. Rice flour is perspective raw stuff for modification of its carbohydrate composition by using these preparations, as it's characterized by high content of polysaccharide (79,1\%), not big amount of saccharides (up to $0,7 \%$ ) and low activity of $\alpha$ - and $\beta$-amylase. That's why, it is expedient to determine the possibility of improving rice bread quality by use of ferment modification od starch with the help of ferments with amylolytic activity.

The aim of research is to justify the possibility of the use of rice flour starch fermentative modification aiming to accumulate mono- and disaccharides with the help of ferments of amylolytic action in the technology of gluten-free bread and determination of its influence on the course of microbiological processes in the dough and the quality of ready made goods.

To solve the goal, the following tasks have been formulated:

- to determine influence of amylolytic action on accumulation of products of rice flour starch hydrolyzation, particularly saccharides and dextrines;

- to research influence of ferments of amylolytic action on microbiological courses in the rice dough, particularly intensity of its fermentation and acid accumulation;

- to determine the effect of supplements on quality markers of readymade gluten-free bread and keeping its freshness.

\section{Materials and methods}

\section{Materials}

Rice flour with "crossed wheat ear" marking was used as the main raw material of making bread for patients with celiac disease, which affirms absence of contact of glutenfree flour with gluten-containing raw materials in production, its domination, the use of equipment designated for grinding "gluten-free" cereals only (CODEX STAN 118-1981, amended 1983) [10]. Ferments of amylolytic action were used for rice flour starch hydrolyzing, particularly $\alpha$-amylase of mushroom origin "Alphamalt VC 5000 SN" (5000 $\mathrm{SKB} / \mathrm{g}$, optimal $\mathrm{pH} 4,7-5,8$, temperature is $40-50^{\circ} \mathrm{C}$, Muhlenchemie, Germany) and glucoamylase "Glucomil", produced by Aspergillus niger (500 AMG/g, optimal pH 3,0-5,5, 
temperature is $40-64{ }^{\circ} \mathrm{C}$, Germany). The following raw materials were used in the research: bread yeast [21], food grade salt (CODEX STAN 150-1985), citric acid [CAC/MISC 62015], drinking water (CODEX STAN 193-1995).

\section{Making of semi-finished product hydrolysate from rice flour}

The temperature of the environment was set as $40^{\circ} \mathrm{C}$ and $\mathrm{pH} 4,7$ to provide with optimal conditions of effect simultaneously of both $\alpha$-amylase and glucoamylase. However, temperature optimum for active yeast functioning while dough fermentation is $28-32{ }^{\circ} \mathrm{C}$, which is not effective for ferments activity. Basing on this, semi-finished producthydrolysate from rice flour has been prepared with the temperature of $40{ }^{\circ} \mathrm{C}$ with the next dough kneading on its basis, that provides with deeper hydrolysis of the starch and allows to enrich the environment with saccharides. Citric acid in the amount of $0,065 \%$ to the mass of flour was used to keep appropriate $\mathrm{pH}$ conditions 4,7. Mass fraction of humidity of semifinished product-hydrolysate from rice flour has been set as $53 \%, 56 \%, 65 \%, 78 \%$. The mixture of rice flour, citric acid, ferments and water has been prepared, which was hydrolyzed in thermostat with $40^{\circ} \mathrm{C}$ up to saccharides accumulation to $5,5-6 \%$. Ferments have been previously dissolved in water with temperature of $25-30^{\circ} \mathrm{C}$ at a ratio of 1:10.

\section{Determination of carbohydrate content}

General amount of saccharides (in terms of maltose) has been determined by Shrol's method [15], the peculiarity is that the amount of cuprum (II) which hasn't reacted is determined by it. Felling's reagent I (solution of $\mathrm{CuSO}_{4}$ with the concentration of 6,925\%) and Felling's reagent II (346g of $\mathrm{KNaC}_{4} \mathrm{H}_{4} \mathrm{O}_{6} \cdot 4 \mathrm{H}_{2} \mathrm{O}$ and $100 \mathrm{~g}$ of $\mathrm{NaOH}$ in $1 \mathrm{dm}^{3}$ of solution) have been added to hydrolysate. After that the solution has been boiled for 2 minutes and quickly cooled. $10 \mathrm{~cm}^{3}$ of $30 \%$ solution of $\mathrm{KI}$ and $10 \mathrm{~cm}^{3}$ of $\mathrm{H}_{2} \mathrm{SO}_{4}$ with concentration of $25 \%$ was added to determine the cuprum amount, which didn't react. Iodine, which stood out, was titrated by 0.1 moles $/ \mathrm{dm}^{3}$ solution of $\mathrm{Na}_{2} \mathrm{~S}_{2} \mathrm{O}_{3}$ to light-yellow color, $2 \mathrm{~cm}^{3}$ of $1 \%$ starch solution was added, and continued to titrate up to blue color disappearing. So, the amount of $\mathrm{Na}_{2} \mathrm{~S}_{2} \mathrm{O}_{3}$ used to titrate $\mathrm{I}_{2}$ is equivalent to the amount of $\mathrm{CuO}$, that didn't react. To determine cuprum amount, which reacted with saccharides, control research was conducted, in which the appropriate amount of water instead of hydrolysate for reactions with Fleming's solutions was taken. The amount of cuprum (II) that reacted and the appropriate amount of saccharides were determined by the difference between the amount of $\mathrm{Na}_{2} \mathrm{~S}_{2} \mathrm{O}_{3}$ used for titration of $\mathrm{I}_{2}$ in the control and work researches. Saccharides content $\mathrm{x}, \%$ to was counted by the formula:

$$
x=\frac{\left(V_{k}-V_{h}\right) \cdot K \cdot 100 \cdot 100}{H(100-W)},
$$

where $\mathrm{V}_{\mathrm{h}} \mathrm{V}_{\mathrm{h}}$ - the amount of 0,1 moles $/ \mathrm{dm}^{3}$ of $\mathrm{Na}_{2} \mathrm{~S}_{2} \mathrm{O}_{3}$ solution, used for titration in the control and work researches, $\mathrm{cm}^{3} ; \mathrm{K}$ - conversion factor to maltose $(5,4) ; \mathrm{H}-$ mass of product, which corresponds to the volume of the hydrolysate, $\mathrm{mg} ; \mathrm{W}$ - mass fraction of humidity in the product, $\%$.

The content of dextrines has been determined by their ability to precipitate with different ethanol concentration in solution [15]. Firstly amylolytic ferments have been inactivated by $96 \%$ of $\mathrm{C}_{2} \mathrm{H}_{5} \mathrm{OH}$ on heated bath to its full evaporation. The next step was to 
remove water-soluble carbohydrates from the batch. To do that, the batch was carried to dimensional bulb for $100 \mathrm{~cm}^{3}$, infused for 1 hour, brought to the mark with water and filtered. Saccharides, which were in the solution were removed by fermentation of bread pressed yeast with the temperature of $25^{\circ} \mathrm{C}$. Glucose, saccharose, fructose, maltose were fermented, and dextrines and pentoses remained. To determine the content of dextrines, three portions of $30 \mathrm{~cm}^{3}$ in which they were precipitated by ethanol were taken with the concentrations of: $1-40 \%$ (amylodextines), $2-65 \%$ (amylo- and erythrodextrines), $3-$ without adding of ethanol (amylo-, erythro-, ahro- and maltodextrines). After thatdextrines have been dissolved by water and hydrolyzed by $20 \% \mathrm{HCl}$ to glucose for 3 hours on boiling heated bath.

Mass fraction of glucose in dextrin hydrolysate has been determined be method of Wilschtetter and Schudl [15]. $30 \mathrm{~cm}^{3} 0,1$ moles $/ \mathrm{dm}^{3}$ of $\mathrm{NaOH}$ solution and $25 \mathrm{~cm}^{3} 0,1$ moles $/ \mathrm{dm}^{3}$ of $\mathrm{I}_{2}$ solution have been added to $10 \mathrm{~cm}^{3}$ of hydrolysate. The bulb was closed by clock glass and left for 15-20 minutes in the dark place. Then 4,5-5 $\mathrm{cm}^{3} 1 \mathrm{moles} / \mathrm{dm}^{3}$ of $\mathrm{H}_{2} \mathrm{SO}_{4}$ solution was added and titrated $0,1 \mathrm{moles} / \mathrm{dm}^{3}$ solution of $\mathrm{Na}_{2} \mathrm{~S}_{2} \mathrm{O}_{3}$. Mass fraction of dextrines, $\mathrm{x}, \%$ per dry matter, was calculated by the following formula:

$$
x=\frac{\left(V-V_{1}\right) \cdot K \cdot 0,009 \cdot 0,9 \cdot 100 \cdot 100}{M(100-W)} .
$$

\section{Bread production}

Bread pressed yeast $(3 \%)$ has been dissolved in water at the temperature of $26-32{ }^{\circ} \mathrm{C}$. Aqueous saline solution with the concentration of $1,2 \%$ at $30^{\circ} \mathrm{C}$ has been prepared and filtered. Rice flour dough has been kneaded on the basis of previously prepared semifinished product-hydrolysate with humidity of $53 \%$ by adding yeast suspension, saline solution and the other part of flour according to recipe. After that, dough batches weighing $350 \mathrm{~g}$ have been formed and fermented in a cabinet for 45 minutes at a temperature of $32^{\circ} \mathrm{C}$ with $85 \%$ relative humidity in air. Baking has been carried out at a temperature of $180^{\circ} \mathrm{C}$ for 25 minutes. Readymade bread has been cooled for 25 minutes and kept at a temperature of $23-27^{\circ} \mathrm{C}$.

\section{Research of the course of microbiological processes in the dough}

Intensity of ethanol fermentation in the dough has been determined by volumetric method with a device AG-1 with the indicator of gas-forming ability, i.e. the volume of $\mathrm{CO}_{2}$ produced, $\mathrm{cm}^{3} / 100 \mathrm{~g}$ at $30^{\circ} \mathrm{C}$, for the period of dough fermentation.

The change of total acidity of the dough has been determined during its fermentation each 15 minutes by titration of 0,1 moles $/ \mathrm{dm}^{3}$ solution of $\mathrm{NaOH} 5 \mathrm{~g}$ of dough semi-finished product, rubbed with $50 \mathrm{~cm}^{3}$ of water, with $1 \%$ of ethanol solution of phenolphthalein to pink coloring [15].

\section{Evaluation of bread quality}

Bread was analyzed not earlier than in 3 hours after baking by the main indicators.

Specific volume was determined as the ratio of volume they occupy to their mass.

Bread staleness has been determined by the following methods: measuring degree of crumb deformation on atomized penetrometer by firm of "AP-4/1" and determination of 
fragility of bread by a whit content, which appeared as a result of shaking on the vibrating mixer.

Porosity has been determined with the help of device [15]. In the piece of the crumb three hollows have been made by a cylinder of the device at a distance not less than $1 \mathrm{~cm}$ from crust, and weighed after. Porosity, \%, was calculated by the formula:

$$
P=\frac{V-\frac{m}{\rho}}{V}
$$

where $\mathrm{V}$ - being general volume of bread hollows, $\mathrm{cm}^{3} ; \mathrm{m}-$ mass of the hollows, $\mathrm{g} ; \rho-$ density of non-porous mass of the crumb, $\mathrm{g} / \mathrm{cm}^{3}$.

Density of non-porous mass for gluten-free bread has been determined by the following way. A hollow was made by device, squeezed thoroughly by wooden piston in a cylinder of a device for removing of pores. Then the hollow in the form of compressed cylinder was weighed and the height of it was measured.

Density of non-porous mass, $\mathrm{g} / \mathrm{cm}^{3}$, was calculated by a formula:

$$
\rho=\frac{m}{\pi \cdot r^{2} \cdot h}
$$

where $\mathrm{m}$ - being the mass of the hollow, g; r - radius of the hollow, $\mathrm{cm}$; $\mathrm{h}$ - height of the hollow, cm.

\section{Results and discussion}

\section{Choice justification of dozing the ferments for modification of rice flour starch}

One of the main problems in rice bread production is its structural mechanical quality indicators $[10,22]$. It is explained by a low level of its own mono- and disaccharides in the flour from rice grains $(0,7 \%)$, which are assimilated by yeast on the initial stage of the dough maturation. Besides, rice flour has a small activity of amylolytic ferments ( $\alpha$ - and $\beta$ amylase), that's why it cannot provide with necessary intensity of ethanol fermentation in gluten-free dough to loosen the dough preparations, as a result the bread made of such flour has a small volume, low porosity and pale crust. Success of technological process course and providing with high quality bakery depend much on the amount of saccharides in the dough, which is the source of nutrition for yeast cells as well as for a process of starch biotransformation under the effect of its own $\alpha$ - and $\beta$-amylase of the flour with maltose formation. That's why we offered to add ferments with amylolytic activity to the dough to raise the amount of saccharides in the dough, which is necessary to provide with the process of fermentation.

Fermentative effect on the starch allows to increase the amount of saccharides in the dough, that leads to intensification of its fermentation process, improving of gas formation during the process of maturation and early stages of baking. It leads to volume increase of the goods, improvement of porosity and texture of crumb $[14,16]$. The choice of ferments is determined by the expected carbohydrate composition of ready product. On analyzing ferment preparations with amylolytic activity we chose mushroom $\alpha$-amylase "Alphamalt VC $5000 \mathrm{SN}$ " with the activity of $5000 \mathrm{SKB} / \mathrm{g}$ and glucoamylase "Glucomil" - 500 AMG/g. So, $\alpha$-amylase hydrolyzes irregularly $\alpha-1,4$ glycoside bonds in the amylose molecule, as a result maltose and products of incomplete hydrolysis of starch - dextrines 
are formed. Unlike $\alpha$-amylase, that can split only unbranched bonds of starch molecule, glucoamylase is able to catalase hydrolytic decomposition of $\alpha$-1,6-glucoside bonds of branched bonds of starch amylopectin. It also transforms dextrines, which are formed under the effect of amylase, to glucose [16-18].

Dosage of ferments depends on their amylolytic activity. As and enhancer for the bread, it is recommended to use mushroom $\alpha$-amylase "Alphamalt VC $5000 \mathrm{SN}$ " in the amount of 250-500 un. SKB per 1 kilo of wheat flour, i.e. 5-10g of the ferment for 5000 un. SKB/g per 100 kilos [19]. But there are no recommendations as for its dosage to rice, as the speed of splitting of starch by amylase from different cultures is different, which depends on the size and shape of starch grains, their structure peculiarities. So the size of rice starch grains is 5-6 microns, at the same time the size of wheat starch grains - 25-35 microns. Evidently, similar dosage of $\alpha$-amylase would effect on rice and wheat starch differently, that would be showed up in formation of new products of hydrolysis. Taking into consideration this fact, the effect of dosage of $\alpha$-amylase "Alphamalt VC $5000 \mathrm{SN}$ " in the amount of $0,01 \%$ to flour mass was studied, which is optimal according to manufacturer's recommendations for accumulation of mono- and disaccharides (Figure 1). Non-yeast dough was prepared of rice flour with the humidity of 53\%. Non-yeast dough of wheat flour with mass fraction of humidity $44,5 \%$ was used as a control example for comparative analysis. The increase of estimated humidity of the rice dough is conditioned by water absorption capacity of the rice grains flour, which is explained by smaller size of starch granules and high content of amylopectin in it (82\%), due to hydrophilic properties the starch granules are very hygroscopic. Duration of fermentation was 3 hours at an environment temperature $40{ }^{\circ} \mathrm{C}$.

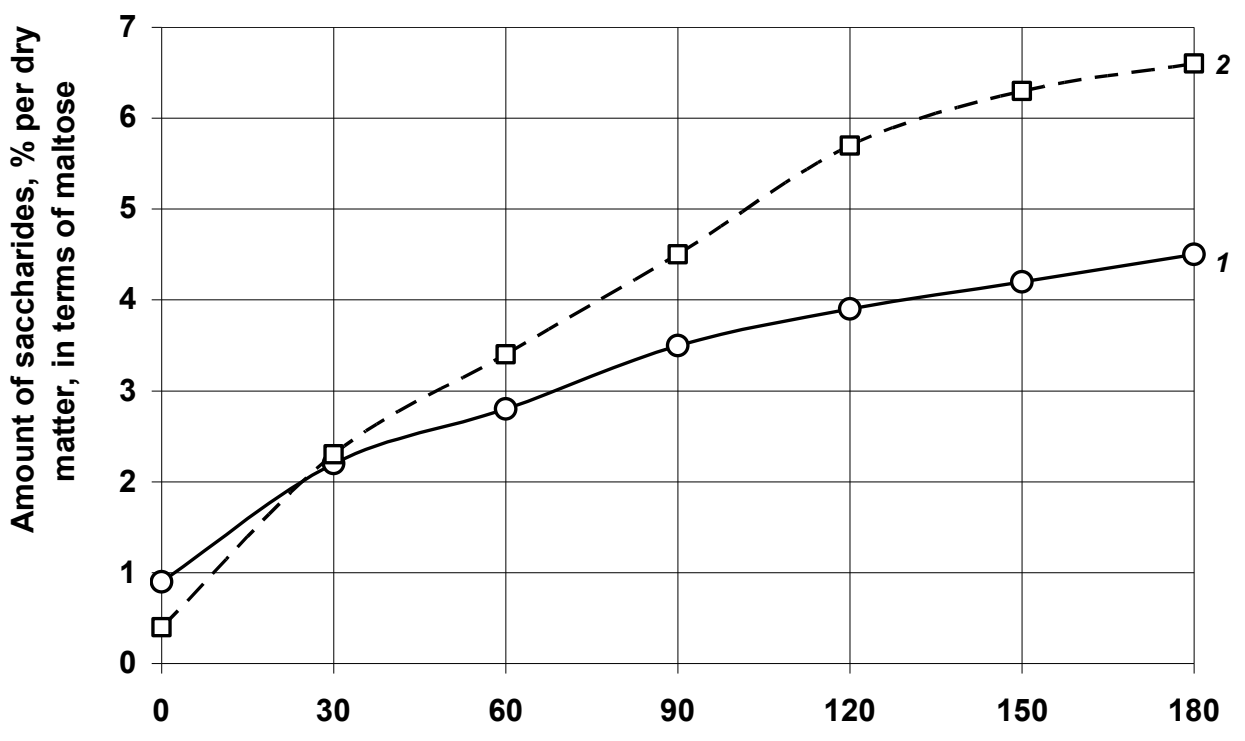

Duration of starch flour hydrolysis, mins.

$-1-0,01 \%$ to mass of wheat flour

$-\square-2-0,01 \%$ to mass of rice flour

Figure 1. Effect of $\alpha$-amylase on accumulation of saccharides in rice and wheat flour dough 
It is determined, that the amount of accumulated saccharides during 3 hours of hydrolysis of rice flour starch was $32 \%$ higher than in the wheat one. It is explained by reduction of dispersion of starch grains starch attacking increases, as their relative surface of contact with ferments increases, as a result the amount of products of hydrolysis is getting higher. That's why the dosage of mushroom $\alpha$-amylase "Alphamalt VC $5000 \mathrm{SN}$ " should be decreased on order to improve the quality of rice flour bread.

We know, that it's needed 5,5-6\% of saccharides from the mass of flour dry matter for the whole cycle of bread preparation [20]. That's why the recommended amount of ferment was determined by accumulation of mono- and disaccharides to the amount mentioned before with the addition of $\alpha$-amylase in the amount of $0,002,0,005$ and $0,007 \%$ to the mass of rice flour (Figure 2).

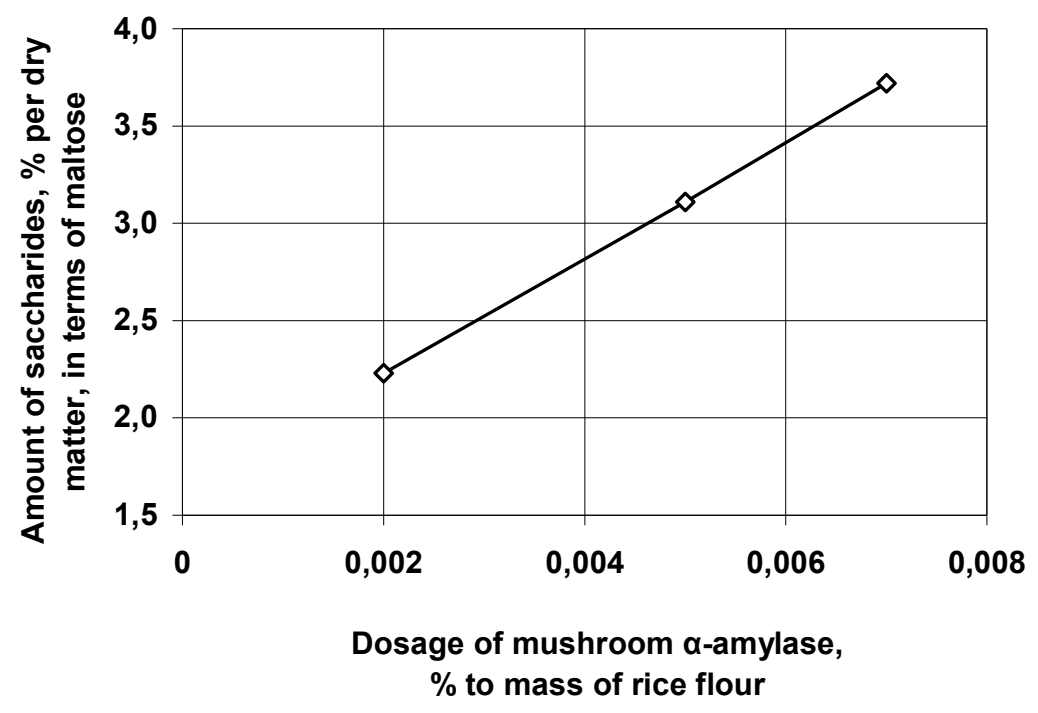

Figure 2. Effect of different dosages of $\alpha$-amylase on saccharides accumulation in the rice dough

It was determined by the results of the research, that adding $\alpha$-amylase of mushroom origin in the amount of 0,005 and $0,007 \%$ to mass of rice flour leads to saccharides accumulation accordingly 3,1 and $3,7 \%$, which is $29-40 \%$ more, than in use of this ferment in the amount of $0,002 \%$. According to the data we got, the recommended dosage of $\alpha$ amylase "Alphamalt VC $5000 \mathrm{SN}$ " is $0,007 \%$ to mass of rice flour, as in such conditions the biggest amount of saccharides is accumulated. However, it is more economically expedient to use $\alpha$-amylase in the amount of $0,005 \%$ to mass of flour, as the amount of saccharides which were formed is slightly different.

The use of $\alpha$-amylase only to enrich dough semi-finished product with saccharides is not efficient because of significant duration of hydrolysis. So, it takes 3 hours to accumulate mono- and disaccharides in amount of 4,5\%. That's why to speed up starch splitting and increasing of mono- and disaccharides, glucoamylase "Glucomil" has been additionally used, recommended dosage of which is $0,7 \mathrm{~g}$ per 1 kilo of starch to hydrolyze 
wheat starch effectively, that in terms of the content of this polysaccharide in the rice flour is $0,065 \%$ to its mass.

On the basis of previous research it is determined that decrease of dosage of $\alpha$-amylase is efficient. That's why, taking into the consideration rice starch properties and its give to effect of amylolytic ferments, in the further research the effect of glucoamylase on saccharides accumulation at its adding in the amount of $0,03 \%$ and $0,05 \%$ to mass of flour to non-yeast dough during fermentation for 3 hours at a temperature of $40^{\circ} \mathrm{C}$, was determined (Figure 3).

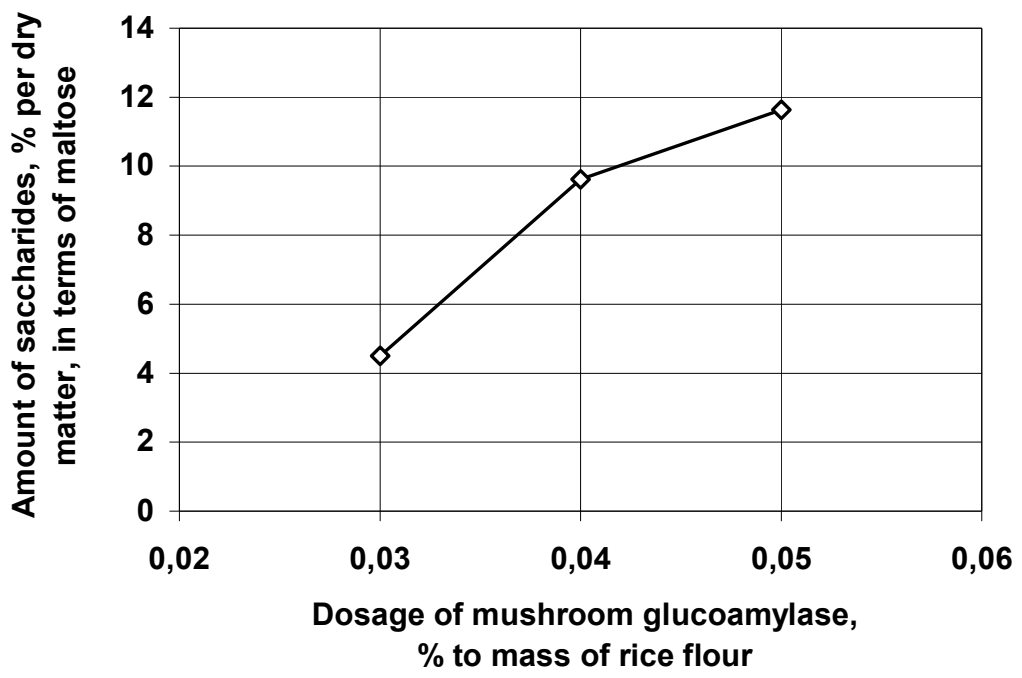

Figure 3. Effect of different dosages of glucoamylase on saccharides accumulation in rice dough

The analysis of the results we got showed, that adding of glucoamylase to rice dough in the study range of dosages helps to increase in it saccharides, which were formed in the process of hydrolyzing of flour starch during 3 hours of fermentation. Herewith the part of accumulated saccharides at adding glucoamylase of $0,04 \%$ and $0,05 \%$ is accordingly $9,6 \%$ and $11,6 \%$ to dry matter. Such amount of saccharides in the dough semi-finished product is ineligible, as the activity of yeast cells are suppressed by the increase of saccharides for more than $6 \%$, as a result of increase of osmotic pressure in the liquid phase of the dough. As well, superabundance of mono- and disaccharides is the reason of activization of the Maillard reaction, and as a result the crust of readymade bread gets brown, which is not peculiar for it. Adding of glucoamylase in the amount of $0,03 \%$ to the flour mass leads to formation of $4,5 \%$ to dry matter of saccharides. That's why it can be assumed, that simultaneous use of $\alpha$-amylase in the amount of $0,005 \%$ and glucoamylase in the amount of $0,03 \%$ to the dough mass will provide with synergic effect, owing to this the fermentative modification of the rice flour starch would be more effective, and the amount of products of its hydrolysis, particularly saccharides and dextrines, would help to intensify dough fermentation and prolong freshness of readymade goods. 
Effect of ferments of $\alpha$-amylase and glucoamylase on carbohydrate content hydrolyzed rice semi-finished product

Taking into consideration amylase and glucoamylase action interval, mentioned by a manufacturer, the optimal temperature for both ferments action is $40^{\circ} \mathrm{C}$ and $\mathrm{pH} 4,7$. As the dough fermentation occurs at a temperature of $28-32^{\circ} \mathrm{C}$, adding of the ferments on the stage of dough kneading is not effective enough. That's why, to accumulate the appropriate amount of saccharides for the whole cycle of bread baking, preparation of semi-finished product-hydrolysate from rice flour at $40^{\circ} \mathrm{C}$ with the following dough kneading on its basis is reasonable. As the rice flour has its active acidity of 5,65 un. of the device, to order to create optimal $\mathrm{pH}$ conditions 4.7 for ferments action, citric acid in the amount of $0,065 \%$ to mass of flour has been used.

We know that hydrolyzing action of amylolytic ferments is seen only at its water combination. Herewith, there is direct dependence between humidity of an environment and the activities of the last ones. Because of that, the effectiveness of fermentative reaction by starch hydrolyzing products accumulation, particularly mono-and disaccharides, has been studied in the course of further researches, with the time of semi-finished producthydrolysate preparation with different humidity (Table 1). Mass fraction of humidity has been determined from a calculation of the use of $100,75,50$ and $25 \%$ of rice flour in accordance to the recipe.

Table 1

Replacement of saccharides during the process of preparation of semi-finished producthydrolysate from rice flour

\begin{tabular}{|c|c|c|c|c|c|c|c|c|}
\hline \multirow{6}{*}{$\begin{array}{c}\text { Hydrolysis } \\
\text { duration, min. }\end{array}$} & \multicolumn{8}{|c|}{ Saccharides content (in terms of maltose), \% to DM } \\
\hline & \multicolumn{4}{|c|}{ With adding of $\alpha$-amylase } & \multicolumn{4}{|c|}{$\begin{array}{l}\text { With adding of } \alpha \text {-amylase and } \\
\text { glucoamylase }\end{array}$} \\
\hline & \multicolumn{8}{|c|}{ Amount of flour, \% from general mass } \\
\hline & 100 & 75 & 50 & 25 & 100 & 75 & 50 & 25 \\
\hline & \multicolumn{8}{|c|}{ Humidity, \% } \\
\hline & $\mathbf{5 3 , 0}$ & 56,0 & 65,0 & $\mathbf{7 8 , 0}$ & $\mathbf{5 3 , 0}$ & 56,0 & 65,0 & 78,0 \\
\hline 0 & 0,41 & 0,32 & 0,21 & 0,12 & 0,41 & 0,32 & 0,21 & 0,12 \\
\hline 30 & 0,90 & 0,95 & 0,98 & 0,96 & 1,12 & 1,88 & 2,64 & 2,32 \\
\hline 60 & 1,50 & 1,88 & 2,26 & 2,03 & 2,54 & 2,83 & 3,12 & 2,98 \\
\hline 90 & 1,72 & 2,34 & 2,95 & 2,71 & 3,05 & 3,76 & 4,52 & 4,20 \\
\hline 120 & 1,95 & 2,85 & 3,80 & 3,34 & 4,22 & 5,06 & 5,90 & 5,36 \\
\hline 150 & 2,40 & 3,32 & 4,25 & 3,80 & 4,86 & 5,68 & 6,50 & 6,09 \\
\hline 180 & 3,11 & 3,80 & 4,60 & 4,20 & 5,11 & 6,03 & 6,95 & 6,45 \\
\hline
\end{tabular}

Data analysis showed, that the content of saccharides increased for 2,6\% DM in nonyeast semi-final product of rice flour with humidity mass fraction of $53 \%$ with $\alpha$-amylase in three hours of hydrolysis, at the same time the use of $\alpha$-amylase and glucoamylase led to their increase to $4,7 \%$ DM. So, simultaneous use of the ferments provides with their synergic effect, which is explained by the hydrolytic action of glucoamylase, which cleaves glucose from starch molecules and products of its incomplete decay, particularly dextrines, formed under the effect of $\alpha$-amylase. Besides, the use of $50 \%$ recipe amount of rice flour for preparation of semi-final product-hydrolysate with $65 \%$ humidity, helped to accumulate more saccharides, because the speed of ferments catalyzed reaction gets higher when humidity mass fraction increases. Further humidity increasing to $78 \%$ is not feasible, as the 
amount accumulated products of starch hydrolysis decreases, that is due to fermentsubstrate ratio violation.

The intensity of dough fermentation depends of saccharides concentration, which are the source of nutrition of yeast. Improvement of their fermentation activity and gas formation is observed at adding of mono- and disaccharides to $6 \%$ [20]. The presence of their bigger amount increases osmotic pressure in the dough liquid phase and leads to plasmolysis of yeast cells (body contraction of living cell with membrane scaling), as a result alcohol fermentation is slowed down, gas formation decreases, dough looseness worsens. Making the conclusion from this, using the data from the Table 1, we can determine, that the optimal concentration of mono- and disaccharides is $5,9 \%$ to DM for high activity of yeast and improvement of gas formation ability of rice flour. To accumulate such amount of saccharides in the semi-finished product the hydrolysis duration is 2 hours (120 minutes) at humidity of $65 \%$, under the conditions of use for its preparation of $50 \%$ of flour from general recipe amount.

$\alpha$-amylase action is directed to starch depolymerization and formation of enough amount of mono- and disaccharides, which will be fermented by the yeast at the dough maturation. Still, the use of mushroom $\alpha$-amylase for making semi-final producthydrolysate from rice flour helps to accumulate dextrines as well. Their redundant content leads to dough clamminess, and as a result, the bread crumb is easily creased, and its elastic properties worsen. That's why, in the further research the accumulation of dextrines during 2 hours of starch hydrolysis for semi-finished product-hydrolysate form rice flour has been determined (Figure 4).

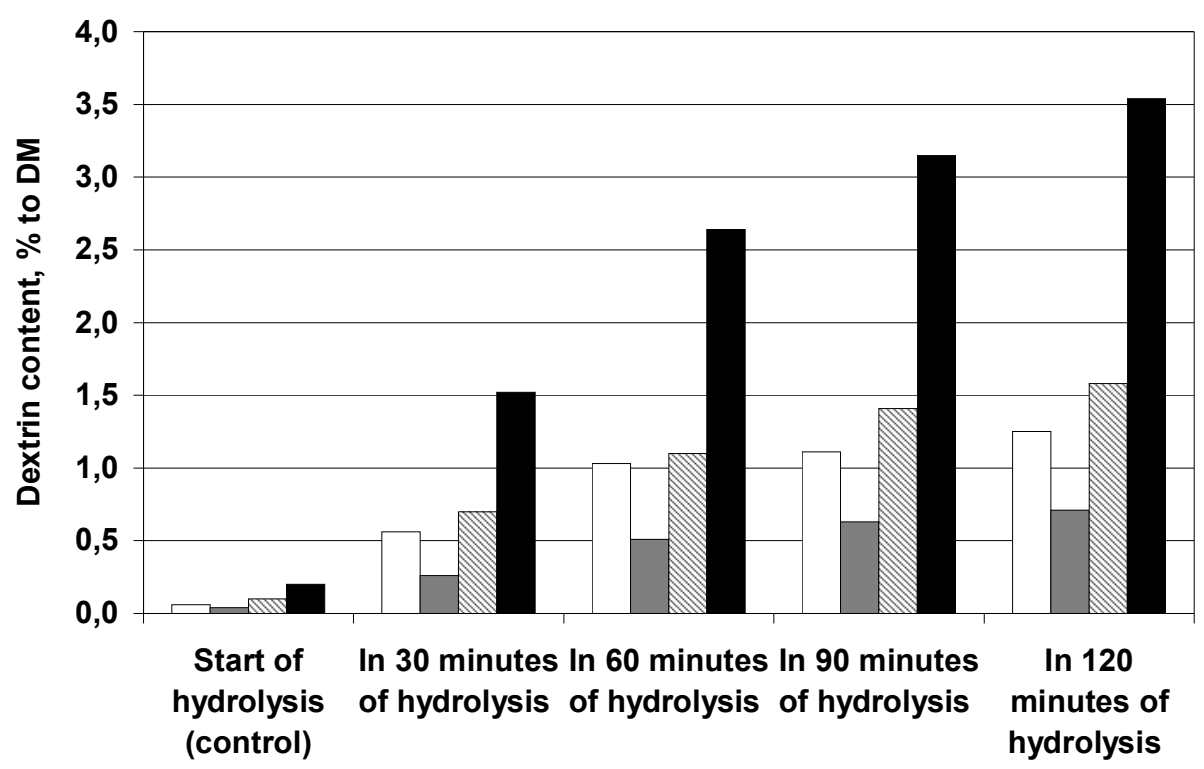

$\square$ Amylodextrins

$\mathbb{Q}$ Achro- and maltodextrines $\square$ Erythrodextrines

- General content of dextrines

Figure 4. The effect of $\alpha$-amylase on dextrin mass fraction 
The analysis of the results we got showed, that general amount of dextrines in production of semi-finished product-hydrolysate increased for $94 \%$ in comparison to control example. At the same time the content of low molecular dextrines, such as achrodextrines and maltodextrines, has increased for 1,48\% DM. It's known, that dextrines are hydrophilic compounds, which increase the amount of bonded moisture and provide with conspicuous effect of the slowing down of starch retrogradation process, that leads to staling of bread.

\section{Effect of fermentative modified rice flour semi-finished product on microbiological processes in yeast dough}

Taking into consideration the fact, that biotechnological processes of living conditions of microorganisms are the main things in the technology of bakery: bread yeast and acid bacteria, it would be expedient to study the effect of additives on the course of technological process and quality of rice bread.

During the research the dough was prepared by non-fermented method, on the basis of semi-finished product-hydrolysate from $50 \%$ of rice flour from its general mass with humidity of $65 \%$. When kneading the dough the other part of flour, yeast in the amount of $3 \%$ and salt have been added. Its estimated humidity was $53 \%$. The dough for the control example has been prepared without adding of ferments of amylolytic action.

The main indicators, that characterize the course of technological process in goods production from yeast dough is gas formation ability, the looseness of bread crumb depends on which, and acid accumulation, which provides with the taste and flavor of readymade products. The obtained results of research of the effect of used semi-finished productshydrolysate from the rice flour on gas formation in the dough (Figure 5) affirm about increasing of carbon dioxide produced, for $57,8 \%$ in comparison to control example. It's explained by adding of extra amount of mono- and disaccharides, formed as a result of hydrolytic starch formation, in consequence of its fermentative modification, which are assimilated by yeast.

We can judge the intensity of fermentation process and dough readiness by increasing of titrated acidity of dough semi-finished products. The analysis of obtained data showed (Figure 6), that in case of use of starch fermentative modification with the help of $\alpha$ amylase and glucoamylase, more intensive increase of acidity is observed in maturation of the dough in the experimental example, in comparison to the control one.

The increase of titrated acidity in the dough, prepared on the basis of semi-finished product-hydrolysate from rice flour, during the whole period of maturation for 1,5 degr, in comparison with control, is caused by adding of citric acid, aiming to provide with optimal $\mathrm{pH}$ conditions for $\alpha$-amylase and glucoamylase action. Besides, in the end of the fermentation process of the dough, using starch fermentative modification, its acidity increases for 0,6 degr, at the same time the control example - only for 0,3 degr. It is probably related to more active vitality of lactic acid bacteria and yeast, that very much depends of the content of nutrient environment, as well as the amount of mono- and disaccharides. 


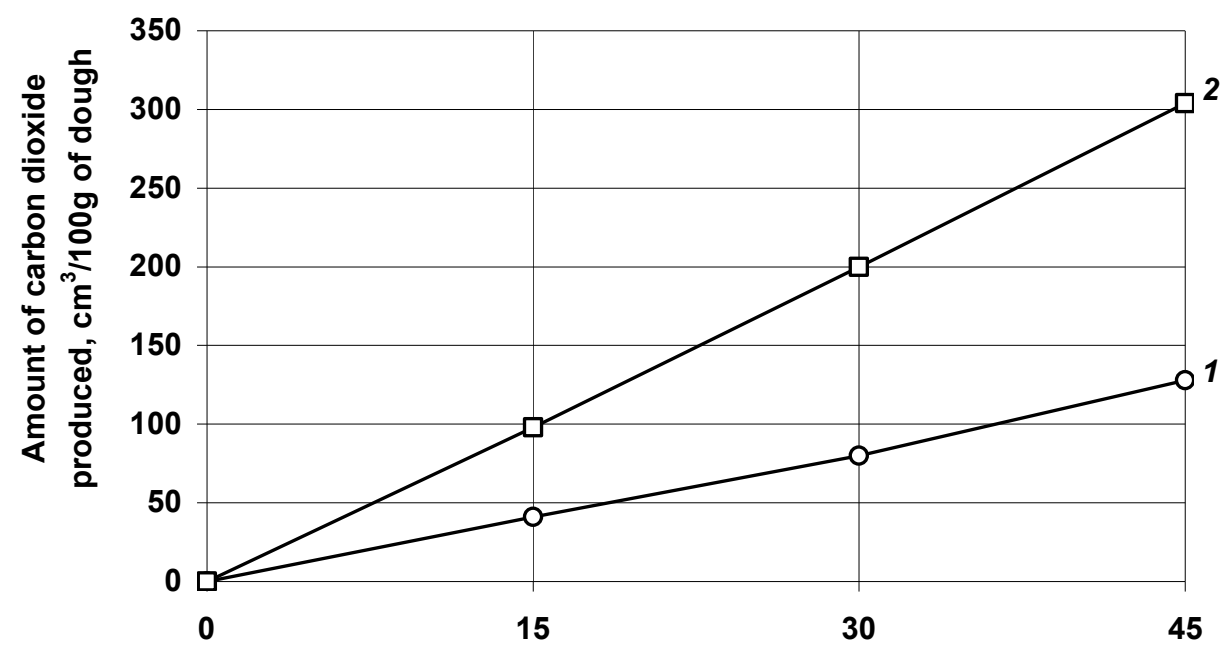

Fermentation duration, mins.

$-0-1$ - Control

$\neg-2$ - With the use of fermentative modification of rice flour

Figure 5. Gas formation ability of rice dough

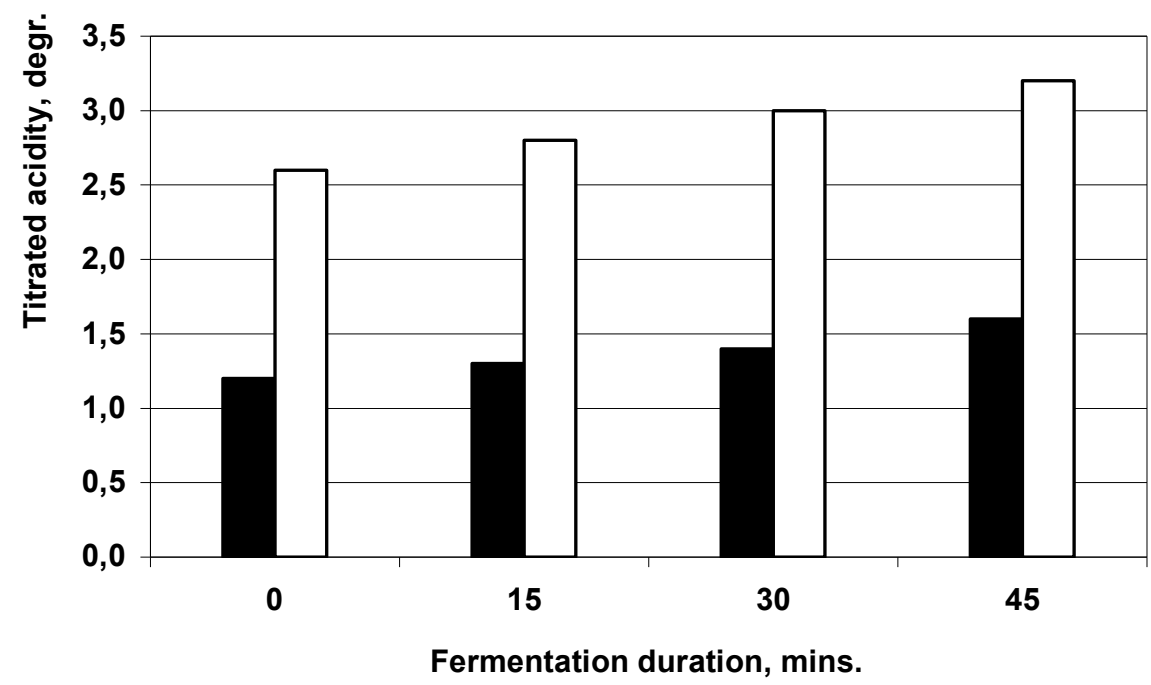

Control

$\square$ With the use of fermentative modification of rice flour

Figure 6. Change of titrated acidity of rice dough 


\section{Effect of fermentative modification of rice flour starch on the quality of readymade bread}

As a result of increasing of readily available sugar, which is assimilated by yeast cells, the process of alcohol fermentation intensifies, in consequence improvement of porosity structure and volume of readymade bread is expected. In the course of further research, the effect of fermentative modification of starch on the quality of readymade goods was determined (Table 2).

Table 2

Rice bread quality score

\begin{tabular}{|l|c|c|}
\hline \multirow{2}{*}{ Score } & \multicolumn{2}{|c|}{ Characteristics of bread quality score } \\
\cline { 2 - 3 } & $\begin{array}{c}\text { Rice flour bread } \\
\text { (without additives) }\end{array}$ & $\begin{array}{c}\text { Bread with the use of semi- } \\
\text { finished product- } \\
\text { hydrolysate from rice flour }\end{array}$ \\
\hline Specific volume, $\mathrm{cm}^{3} / \mathrm{g}$ & 1,27 & 1,44 \\
\hline Acidity, degr. & 1,3 & 2,8 \\
\hline Porosity, \% & 36,7 & 41,4 \\
\hline Fragility, \% & & 1,30 \\
\hline in 3 hrs & 2,50 & 2,60 \\
\hline in 24 hrs & 6,95 & \\
\hline $\begin{array}{l}\text { Bread crumb deformation, } \\
\text { un. of penetrometer }\end{array}$ & & 59 \\
\hline in 3 hrs & 48 & 46 \\
\hline in 24 hrs & 34 & \\
\hline
\end{tabular}

Analysis of readymade products shows positive effect of the use of starch fermentative modification of rice flour on the change of structural mechanical properties of readymade goods. Bread freshness is one or the main scores of its quality and storage suitability. It's determined by the results of research of crumb deformation level, that after cooling (after 3 hours of storage), the use of the offered technology of rice bread provides with increasing of softness for $18 \%$, and after 24 hours - for $24 \%$. Herewith, decrease of bread penetration degree with the use of starch fermentative modification is less intensive, than the control one. It's explained by accumulation of low molecular dextrines when preparing of semifinished product-hydrolysate from rice flour under the effect of mushroom $\alpha$-amylase (Figure 4), that provides with longer period of keeping the readymade products fresh.

Better keeping of the freshness of the experimental example of rice bread in comparison to the control one, is confirmed by the results of determining of their fragility. It's determined, that the use of rice flour starch fermentative hydrolysis in bread production leads to decreasing of this score for 1,9 times, in comparison to control for freshly baked products.

Improvement of specific volume and porosity of readymade bread is stipulated by intensification of gas formation process in the dough, with the use of $\alpha$-amylase and glucoamylase, because of increasing of carbon dioxide amount, produced in the process of its fermentation. But the analysis of obtained results shows, that the specific volume and porosity of gluten-free bread, prepared on the basis of semi-finished products-hydrolysate, 
increases only for $13,4 \%$ and $12,5 \%$ in comparison to control example, which won't allow to improve the quality of readymade products, at the same time gas formation increases for $57,8 \%$ (Figure 5). Determined dependence can be explained by the thing, that as a result of absence of gluten carcass, that has elastic properties, it has a low gas retention capacity, that's why carbon dioxide accumulation is ineffective. Carbon dioxide, which is formed in alcohol fermentation, causes the pressure in dough preparation, as a result cracks appear on its surface, through which the main loses of $\mathrm{CO}_{2}$ occur, as a result the dough is irreversibly depleted.

Obtained data testify to the necessity of enhancer, that could improve dough rheological properties. That's why further researches will be associated with the development of measures aiming to improve gas retaining capacity in the rice flour dough. One of the ways to improve bread quality for patients with celiac disease might be the use of surfactants.

\section{Conclusions}

As a result of research, the expediency of hydrolysis of rice flour starch by amylolytic ferments in bread technology for patients with celiac disease has been determined. The dosage of mushroom $\alpha$-amylase in the amount of $0,005 \%$ and glucoamylase $-0,03 \%$ to mass of rice flour helps to accumulate saccharides in the amount of 5,5-6\%, which are necessary for intensification of the course of microbiological processes in the dough. For more complete starch hydrolysis, the expediency of preparation of semi-finished producthydrolysate with the moisture content of $65 \%$ from $50 \%$ of rice flour from its recipe amount with the further kneading of the dough on its basis. The use of rice flour starch fermentative modification in bread technology intensifies gas formation and acid accumulation in the process of dough maturation, as a result, readymade goods are characterized by improved structural mechanical quality scores. Besides, the production of bread using the ferment of $\alpha$-amylase allows longer shelf life.

\section{References}

1. Laureati M., Giussani B., Pagliarini E. (2012), Sensory and hedonic perception of gluten-free bread: Comparison between celiac and non-celiac subjects, Food Research International, 46, pp. 326-333.

2. Elgeti D., Nordlohne S.D., Föste M., Besl M., Linden M.H., Heinz V. et al. (2014), Volume and texture improvement of gluten-free bread using quinoa white flour, Journal of Cereal Science, 59, pp. 41-47.

3. Pruska-Kedzior A., Kedzior Z.,Goracy M., Pietrowska K., Przybylska A., Spychalska K. (2008), Comparison of rheological, fermentative and baking properties of glutenfree dough formulations, Eur Food Res Technol, 227, pp. 1523-1536.

4. Lamireau T., Clouzeau H. (2013), Epidemiologie de la maladie coliaque, Pathologie Biologie, 61(2), pp. 1-4

5. Remesy Ch., Zeenhardt F., Fordet A. (2015), Donner un nouvel avenir au pain dans le cadre d une alimentation durable et preventive, Cahiers de nutrition et de dietetique, 50, pp. 39-46. 
6. Hatta E., Matsumoto K., Honda Y. (2015), Bacillolysin, papain, and subtilisin improve the quality of gluten-free rice bread, Journal of Cereal Science, 61, pp. 41-47.

7. Demirkesen I., Mert B., Sumnu G., Sahin S. (2010), Rheological properties of glutenfree bread formulations, Journal of Food Engineering, 96, pp. 295-303.

8. Olives J.P. (2006), Maladie cœliaque: nouvelles perspectives, Mt. pédiatrie, 9(2), pp. 87-98.

9. Houben A., Hochstotter A., Becker T. (2012), Possibilities to increase the quality in gluten-free bread production: an overview, Eur Food Res Technol, 235, pp. 195-208.

10. Nunes Maria.H.B., Moore M.M., Ryan Liam A.M., Arendt E.K. (2009), Impact of emulsiWers on the quality and rheological properties of gluten-free breads and batters, Eur Food Res Technol, 228, pp. 633-642.

11. Renzetti S., Bello F.D., Arendt E.K. (2008), Microstructure, fundamental rheology and baking characteristics of batters and breads from different gluten-free flours treated with a microbial transglutaminase, Journal of Cereal Science, 48, pp. 33-45.

12. Purhagen J.K., Sjoo M.E., Eliasson A.Ch. (2012), The anti-staling effect of pregelatinized flour and emulsifier in gluten-free bread, Eur Food Res Technol, 235, pp. 265-276.

13. Hryshchenko A.M., Udvorheli L.I., Mykhonik L.A., Kovalevska Ye.I. (2010), Doslidzhennia strukturno-mekhanichnykh vlastyvostei bezbilkovoho tista $\mathrm{Z}$ kamediamy huaru i ksantanu, Kharchova nauka i tekhnolohiia, 1(10), pp. 63-65.

14. Kapreliants L.V. (2009), Ispolzovanie fermentov v khlebopechenii, Kharchova nauka $i$ tekhnologiia, 1(6), pp. 34-38.

15. Drobot V.I., Yurchak V.H., Bilyk O.A., Bondarenko Yu.V., Hryshchenko A.M., Zinchenko I.M., Kambulova Yu.V., Makhynko V.M., Mykhonik L.A., Falendysh N.O., (2006), Tekhnokhimichnyi kontrol syrovyny ta khlibobulochnykh i makaronnykh vyrobiv, Kondor, Kyiv.

16. Goesaert H., Slade L., Levine H., Delcour J.A. (2009), Amylases and bread firming - an integrated view, Journal of Cereal Science, 50, pp. 345-352.

17. Konsula Z., Liakopoulou-Kyriakides M. (2004), Hydrolysis of starches by the action of an a-amylase from Bacillus subtilis, Process Biochemistry, 39, pp. 1745-1749.

18. Kapreliants L.V. (2009), Fermenty v pishchevykh tekhnologiiakh, Odesa.

19. Popper L. (2009), Fermentnaia obrabotka muki, Khleboprodukty, 6, pp. 46-49.

20. Drobot V.I. (2002), Tekhnolohiia khlibopekarskoho vyrobnytstva, Lohos, Kyiv.

21. Kalmus S. (2017), What Is the Difference Between Brewer's Yeast \& Baker's Yeast?, available at:

https://www.livestrong.com/article/176197-what-is-the-difference-between-brewersyeast-nutritional-yeast/

22. Yano H., Fukui A., Kajiwara K., Kobayashi I., Villeneuve M. (2017), Development of gluten-free rice bread: Pickering stabilization as a possible batter-swelling mechanism, Food Science and Technology, 79, pp. 632-639.

23. Hera E., Martinez M., Gómez M. (2013), Influence of flour particle size on quality of gluten-free rice bread, Food Science and Technology, 54(1), pp. 199-206. 